Revista Española de Antropología Americana ISSN: 0556-6533

\title{
Técnicas analíticas en el estudio de iconografías secuenciales en Perú y México
}

\author{
Laura López Estupiñán ${ }^{1}$
}

Recibido: 21 de agosto de 2018 / Aceptado 12 de diciembre de 2019

Resumen. Este artículo es un aporte a los análisis iconográficos en murales arqueológicos elaborados por dos sociedades de la costa norte peruana y el centro de México. Para avanzar en la comprensión contextual de las iconografías secuenciales, conocidas también como la serie de secuencias iconográficas que representan movimiento en murales arqueológicos, se aplican dos técnicas analíticas, la morfometría geométrica (técnica matemática que permite la visualización de los cambios espaciales de los trazos y formas de las representaciones iconográficas) y la cronofotografía (técnica fotográfica que comunica la sensación de dinamismo de los cuerpos en un tiempo determinado). Con el fin de garantizar la animación de las representaciones contenidas en los murales arqueológicos de Tula (México) y Huaca de la Luna (Perú), la investigación recurrió a la experimentación digital en los software Fantamorph, MorphX, Adobe Photoshop CS6 y Adobe Premiere Pro CS6.

Palabras clave: Iconografía secuencial; imagen en movimiento; morfometría; cronofotografía.

\section{[en] Analytical Techniques in the Study of Sequential Iconographs in Peru and Mexico}

\begin{abstract}
This article is a contribution to the iconographic analyzes in archeological murals prepared by two societies of the Peruvian north coast and central Mexico. To advance the contextual understanding of sequential iconographies, also known as the series of iconographic sequences that represent movement in archaeological murals, two analytical techniques are applied, geometric morphometry (mathematical technique that allows the visualization of the spatial changes of the strokes and forms of iconographic representations) and chronophotography (photographic technique that communicates the sensation of dynamism of the bodies in a given time). In order to guarantee the animation of the representations contained in the archaeological murals of Tula (Mexico) and Huaca de la Luna (Peru), the research resorted to digital experimentation in Fantamorph, MorphX, Adobe Photoshop CS6 and Adobe Premiere Pro CS6 software.
\end{abstract}

Keywords: Sequential iconography; image in movement; morphometry; chronophotography.

Sumario. 1. Introducción. 2. Sitios arqueológicos con iconografías secuenciales en murales de América. 3. Los métodos de investigación en el análisis de iconografías secuenciales. 4. Aproximaciones a la imagen en movimiento desde la aplicación de técnicas analíticas. 5. Consideraciones finales. 6 . Referencias.

Museo Arqueológico de Tunja. Grupo Interdisciplinario de Investigaciones Arqueológicas e Históricas de la UPTC.1aloes2@gmail.com 
Cómo citar: López Estupiñán, Laura. 2020. “Técnicas analíticas en el estudio de iconografías secuenciales en Perú y México". Revista Española de Antropología Americana 50: 9-22.

\section{Introducción}

La representación de movimiento en la iconografía arqueológica de América fue desarrollada por Makowski (2001), Morales (2003), Mires (2006), Golte (2009) Hart (2010), y Campana (2015), quienes se enfocaron en la secuencia narrativa. Por su parte, López (2016) recurre a la cronofotografía, técnica para "estudiar la locomoción de los animales sintetizada en la representación plástica del dinamismo" (Reyes 1993: 100), con el fin de estudiar la representación de movimiento presente en los paneles del frontis norte del sitio arqueológico Huaca de la Luna, Perú. Al aplicar la técnica, encuentra que la cronofotografía ${ }^{2}$ no permitía profundizar y explicar las diferencias iconográficas mínimas entre cuadros o fotogramas de una misma representación, por lo que incorpora la morfometría geométrica ${ }^{3}$ como técnica matemática que permite obtener una descripción precisa y certera de las formas, para estudiar las variaciones entre representaciones y cuadros.

Aunque la cronofotografía y la morfometría geométrica son técnicas aplicadas en la Biología (Zelditch et al. 2004; Benitez y Püschel 2014), la Dinámica (Reyes 1993) y la Antropología Visual (Bateson y Mead 1937; Gallardo 2002), su uso en la Arqueología no fue contemplado como técnica analítica para el análisis iconográfico hasta 2016, pese a que se reconocía la representación de movimiento en la iconografía prehispánica. Hablar de imagen en movimiento no sólo remite a los principios de la cronofotografía planteados por Marey entre 1880 y 1899, replicados posteriormente por Muybridge (Reyes 1993), sino que "amplia las formas narrativas y retóricas que implican los códigos de temporalidad" (Hernández 2006: 197), nos permite comprender cambios en el pensamiento y las formas de relación de la imagen con los hombres en la prehistoria.

Para el caso de Europa, Azéma (2010) ya mencionaba que durante el Paleolítico se elaboraron 4634 representaciones de movimiento, provenientes de 141 cuevas en Francia, las cuales corresponden a un periodo de 36000 a 9000 años antes del presente. Para el caso de América, las apariciones de imagen en movimiento en murales arqueológicos corresponden a periodos tardíos, 1200 años antes del presente, en sociedades estatales como los moche y los tolteca. Si bien López (2016) propone

\footnotetext{
La cronofotografía permite capturar el desplazamiento de los cuerpos en una frecuencia temporal, mediante un proceso de descomposición del movimiento, facilitando el análisis de series y secuencias de imágenes representadas en escalones, paneles o murales arquitectónicos de sitios arqueológicos. Esta técnica "comunicaba la sensación del dinamismo al mostrar, en una misma imagen, el desdoblamiento minucioso de las fases sucesivas del desplazamiento de los objetos y cuerpos en movimiento (Reyes 1993: 104). Su aplicación en el análisis iconográfico permite evidenciar diferencias entre series o sucesiones de imágenes definidas por coherencia, simplicidad y similitud de sus formas.

3 Al "remover los efectos de la escala, la rotación y traslación de un objeto", la morfometría geométrica "proporciona herramientas gráficas para la cuantificación y visualización de la variación morfológica intra e interespecífica" (Benitez y Püschell 2014: 998) del objeto, la imagen o los cuerpos. Su aplicación en el análisis iconográfico permite visibilizar las variaciones de los ángulos y los cambios de posición de los puntos que conforman las imágenes, cuantificando el movimiento y los cambios de las formas.
} 
representaciones de movimiento en las imágenes, a partir del análisis de iconografías secuenciales, con la replicación de las técnicas de cronofotografía y morfometría geométrica en otros sitios arqueológicos de Perú (Huaca Arco iris) y México (Tula), se confirma la existencia de imágenes en movimiento en murales de estructuras arquitectónicas de carácter público en América.

\section{Sitios arqueológicos con iconografías secuenciales en murales de América}

Al comprobar que en murales y vasijas de cerámica acampanada de Huaca de la Luna se evidenciaba la intencionalidad de transmitir movimiento al observador, se inició -entre 2015 y 2016- un recorrido por sitios arqueológicos de México para replicar el método. Para ello, se identificaron sociedades prehispánicas con características similares como una organización estatal, con estructuras arquitectónicas complejas y plazas ceremoniales que permitiesen comprender la iconografía del lugar, es el caso de Huaca de la Luna y Tula.

\subsection{Huaca de la Luna, Escalón 3 del frontis norte}

La investigación inicial se realizó en las Huacas de Moche, un complejo arqueológico con características de ciudad, capital del Estado Territorial Moche del sur, abandonado hacia el año 850 d.C., en la costa norte peruana. Los análisis iconográficos se realizaron en Huaca de la Luna (Figura 1), específicamente en la Plataforma I y el frontis norte de Plaza 1, conocido como "el espacio arquitectónico más grande del complejo arqueológico, que abarca un área de $11.500 \mathrm{~m}^{2}$ " (Uceda et al. 2010: 35).

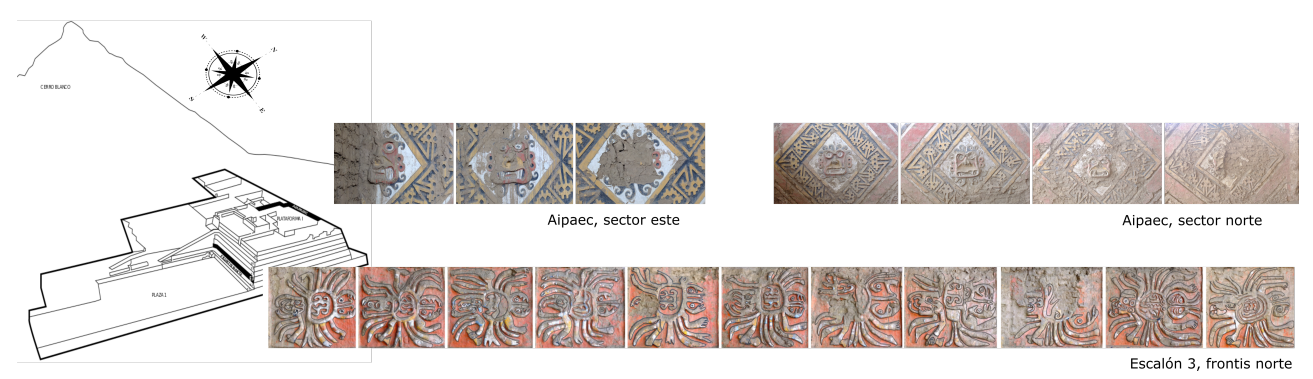

Figura 1. Iconografías secuenciales trabajadas en Huaca de la Luna, Perú.

Aunque Uceda, Gayoso y Tello (2010) realizaron análisis iconográficos de modo vertical en el frontis norte, los análisis y lecturas de tipo horizontal en un mismo escalón se obviaron por considerarse errores de los artesanos a la hora de la elaboración. Las características del frontis permiten confirmar que sólo los escalones 3 , 4, 5, parte del 6 y 7 cuentan con una división intencional de los cuadros, marcando diferencias entre cuadros y representaciones.

Al realizar el análisis horizontal de cada escalón o panel, se encontró que las representaciones polícromas de adobe en alto relieve no son uniformes y varían entre escalones, siendo los escalones 3, 5, parte del 6 y 7 evidencias de iconografías secuenciales. Por las afectaciones de los murales y los estados de conservación no fue 
posible realizar un análisis detallado de morfometría, razón por la que se seleccionó el Escalón 3.

Con una altura promedio de 2,50 m y una longitud de 74,30 m, el Escalón 3 está conformado por 31 fotogramas en total, de los cuales 21 están parcialmente conservados. Al interior de cada fotograma se encuentra una representación zoomorfa que caracteriza un arácnido con rasgos antropomorfos. Al realizar el análisis cronofotográfico y morfométrico de la representación se identificaron dos personajes en un mismo ser, conformado por dos partes independientes en un mismo cuerpo (dos cabezas, dos manos, apéndices locomotores, dos objetos, un vientre, ojos, quelíceros (primer par de apéndices bucales) y pedipalpos (segundo par de apéndices bucales).

La presencia de iconografías secuenciales en Huaca de la Luna se evidencia también en la Plataforma 1 (ver Figura 1), específicamente en murales de adobe polícromos con representaciones del Aiapaec o dios de la Montaña, como se conoce a una de las deidades moche.

\subsection{Tula (México)}

Para el caso de México se eligió Tula por ser "uno de los centros urbanos más extensos de Mesoamérica, con cerca de $15 \mathrm{~km}^{2}$ durante su apogeo, entre 900-1150 d.C." (Cobean y Mastache 2007: 30). En Tula Grande se encuentran dos murales en piedra que conforman el Edificio B, en sus lados Este y Norte. Los murales se encuentran conformados por un tablero integrado por lápidas lisas y con relieves (Figura 2). Allí se muestran representaciones diversas que parecen mostrar seres míticos (hombre-felino-pájaro-serpiente), falcónidas (águilas y buitres o ¿zopilotes?), felinos (¿pumas o jaguares?) y coyotes, los cuales parecen corresponder al Posclásico (Jiménez 2008: 73).

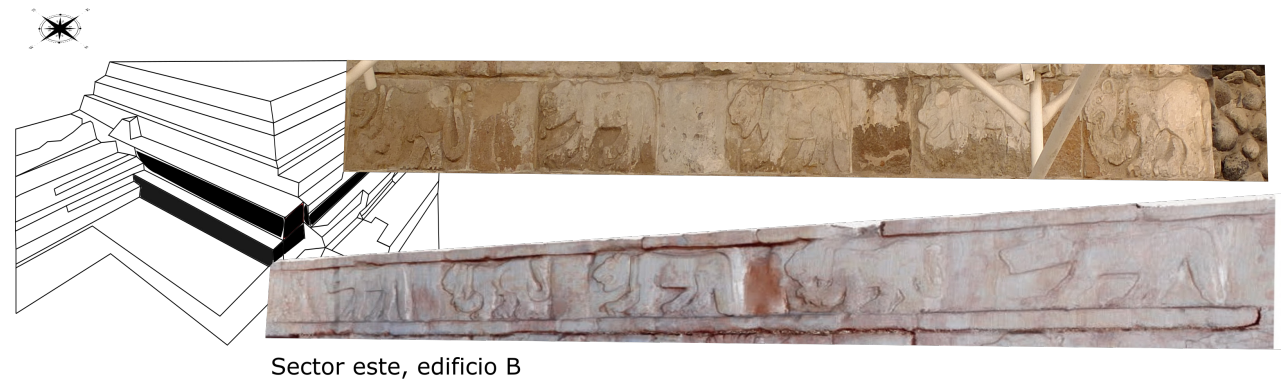

Figura 2. Iconografías secuenciales trabajadas en Tula, México.

Por el estado de conservación del mural, se escogieron las representaciones de los felinos y coyotes (ver Figura 2), los cuales están dispuestos en paneles horizontales en sentido Este y Norte. El lado Este del mural donde se encuentran los relieves mide $18,15 \mathrm{~m}$ de largo y 1,50 m de alto, corresponde a una serie continua de dos representaciones, una con rasgos de felinos y la otra con rasgos de coyotes, con posiciones diferenciadas que se repiten intercaladamente por ¿coyotes? y felinos. En el panel, sentido Este-Oeste, aparece una imagen que toma los rasgos de las dos representaciones principales para un total de 14 imágenes. 


\section{Los métodos de investigación en el análisis de iconografías secuenciales}

Analizar la iconografía secuencial en murales de estructuras arquitectónicas de Perú y México requiere de un trabajo interdisciplinar que se enriquece con estudios comparativos y multisituados (geográficamente hablando). Como ejercicio investigativo implicó inicialmente un proceso de experimentación, mediante la aplicación de métodos arqueológicos, fotométricos y de animación en los murales policromos de Huaca de la Luna (Perú) y, posteriormente, su replicación en los murales de Huaca Arco Iris (Perú) y Tula (México).

La implementación de métodos arqueológicos hizo necesaria la conceptualización de términos propios de la fotometría y la animación en los sitios arqueológicos. La caracterización cronológica-secuencial de los primeros registros arqueológicos de los murales (fotografías y dibujos del Proyecto Arqueológico Huacas del Sol y la Luna), permitió identificar iconografías secuenciales en los escalones 3, 5, 6 y parte del 7 del frontis norte y en los murales laterales de la Plataforma I de Huaca de la Luna.

La disposición de las estructuras arquitectónicas en Huaca Arco Iris y Tula, permitió identificar murales con iconografías secuenciales, conformadas por paneles, fotogramas y series de fotogramas. Se define como panel la franja horizontal que contiene las representaciones o fotogramas, compuesto por cuadros, banda superior y banda inferior. Los fotogramas corresponden a cada una de las representaciones o imágenes que conforman el panel, se encuentran dentro de cuadros y están intencionalmente divididos; generalmente son cuadrados, rectangulares o romboides. $\mathrm{La}$ serie de fotogramas corresponde a los fotogramas que guardan mayores similitudes entre sí, facilitan el registro, la lectura y evidencian la secuencia iconográfica.

Unificado el lenguaje y definidos los conceptos, se generó un protocolo de registro de iconografías en campo que permitió la identificación, enumeración, el registro fotográfico individual y por series de fotogramas, las mediciones de cuadros (contenedores rectangulares, cuadrados y romboides de las representaciones) y partes de los personajes (cabezas, apéndices, ojos, quelíceros, olas, nariz, contorno de boca, etc.), el dibujo sobre fotografías, el análisis de isovistas y la revisión de documentación relacionada con iconografía e imagen en movimiento.

En cuanto al espacio arqueológico, hay que mencionar las particularidades de los dos sitios. Los murales de Tula se encuentran en un espacio privado, de poco acceso y posiblemente cubierto, mientras los murales de Huaca de la Luna se encuentran en espacio abierto y de acceso (visual) público. Al hacer parte de estructuras en espacios abiertos, es relevante el análisis de isovistas, puesto que permite comprender la experiencia visual de la persona, al moverse en el campus y, por ende, establecer las distancias mínimas y máximas para una observación adecuada. La precisión en la construcción de los espacios evidencia la planeación, diseño y comunicación del mensaje iconográfico en los dos sitios arqueológicos, uno privado y otro público. Para el caso de Huaca de la Luna, el tamaño de los paneles, los relieves y colores utilizados permiten una visibilidad aceptable desde todos los extremos de la plaza, cumpliendo su función pública en un área con capacidad para 10.000 personas (Meneses et al. 2009).

En cuanto al análisis iconográfico, el procesamiento de la información recogida en campo permitió identificar variaciones morfométricas entre representaciones que a simple vista parecían similares y que los investigadores del sitio habían documentado como "diferentes estilos del maestro artesano" (Meneses et al. 2009: 97). 
Ante la situación, se recurrió a métodos fotométricos con el fin de controlar posibles deformaciones de las imágenes, definir con precisión las formas, dimensiones y posiciones en el espacio de cada una de las representaciones.

La fase de campo requirió codificar cada fotograma con el fin de generar un archivo independiente que permitiese atribuir medidas, variaciones angulares de cada parte y el estado de conservación. Luego se hizo un registro sistemático de fotografía, manteniendo la distancia frontal entre el panel y la cámara. Se tomaron fotos a $\operatorname{los} 2,8,10,20,40$ y 100 metros para avanzar en el análisis de isovistas. También se tomaron fotografías por series, fotogramas y contexto, en planos generales y en detalle para facilitar el análisis iconográfico.

Terminado el registro fotográfico, se continuó con el dibujo digital sobre fotografía con el fin de no alterar, recrear o inventar la imagen. Cada fotograma permitió conformar un archivo en Photoshop compuesto por capas diferenciadas (según las partes de cada representación), cada capa se dibujó mediante el uso de tabla digitalizadora y se generaron dos convenciones de trazos: continuos (en las imágenes que estaban completas) y discontinuos (en las partes de los murales que no están en buen estado de conservación).

Siguiendo los principios de descomposición gráfica planteados por Azéma (2007), que facilitan la identificación de las variaciones morfométricas en cada una de las partes, así como las permanencias en las formas generales de las representaciones, se elaboraron capas diferenciadas de cada uno de los fotogramas, permitiendo descomponer el Aiapaec, de la Plataforma I en Huaca de la Luna, en ojos, boca, contorno de boca, orejas y olas. A su vez, el ser arácnido del Escalón 3 se descompone en apéndices locomotores, cabeza anterior, cabeza posterior, mano anterior, objeto mano anterior, objeto mano posterior, mano posterior, cefalotórax, pedipalpos, quelíceros y ojos. En cuanto a los felinos y coyotes de Tula, la descomposición gráfica obedece a cabeza, lengua, orejas, ojos, collar, cola, patas anteriores y posteriores.

Al terminar el dibujo digital de cada una de las representaciones, se continuó con el proceso de vectorización ${ }^{4}$ de las imágenes, se trabajó cada representación sobre un plano cartesiano ${ }^{5}$ con el fin de ubicar las partes que más variaban de posición con respecto a los ejes $\mathrm{x}$ e $\mathrm{y}$. Todos los puntos donde aparecían los extremos de cada una de las partes fueron sistematizados en una base de datos, permitiendo identificar las distancias, ángulos y cambios en las posiciones.

El análisis confirmó que ninguna representación es igual a otra, ni en forma, ni en posición, por lo cual se deduce la intencionalidad de transmitir una ilusión de movimiento y transformación de las imágenes, ilusión dada al representar variaciones entre $10^{\circ}$ y $70^{\circ}$ en las extremidades del personaje del Escalón 3 de Huaca de la Luna (Perú), entre $20^{\circ}$ y $90^{\circ}$ en Tula (México), entre $10^{\circ}$ y $50^{\circ}$ en Huaca Arco Iris (Perú).

El trabajo manual y digital realizado constituye la base del análisis morfométrico, que permite evidenciar de manera física y matemática los cambios y variaciones de cada una de las partes del fotograma, y por ende de las secuencias iconográficas que conforman el panel. El mismo sistema es utilizado por los programas de animación

La vectorización de imágenes consiste en convertir los pixeles en vectores de posición y segmentos de rectas que facilitan la identificación de cambios y permanencias entre cada una de las partes que conforman las representaciones.

5 El plano cartesiano permite la ubicación de un punto en un plano respecto a dos ejes, uno horizontal (x) y uno vertical (y). 
que materializan la ilusión de movimiento, tales como morphX y Fantamorph, programas que trabajan desde el análisis de contornos de Fourier, con principios vectoriales que permiten evidenciar la correlación de landmarks o puntos de referencia, los cambios espaciales y morfométricos cuadro a cuadro (López y Rodríguez 2016). El uso de morphX permitió visualizar variaciones morfométricas entre dos fotogramas, mediante vectores resaltados en color verde que indicaban los cambios de la representación en el mismo espacio; mientras que Fantamorph evidenció cambios en series de fotogramas mediante correlaciones de puntos de referencia (Figura 3).
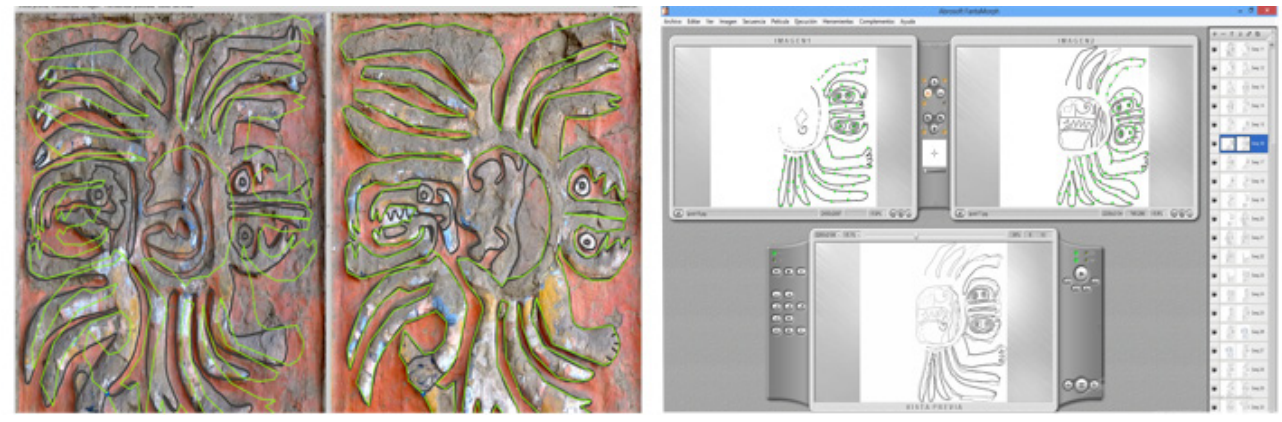

Figura 3. Variaciones morfométricas entre fotogramas. Trabajo en morphX y fantamorph.

El uso de distintos programas de animación facilitó su aplicabilidad según los soportes arqueológicos. Si bien encontramos estructuras lineales en la iconografía mural, las vasijas acampanadas tienen estructuras circulares que condicionan la composición y descomposición del movimiento en aplicaciones digitales. Fantamorph y morphX permiten la minuciosidad en el análisis cronofotográfico y morfométrico de iconografías secuenciales en murales, mientras que Adobe Premiere Pro y Adobe Photoshop funcionan mejor en la animación de iconografías secuenciales presentes en la boca ancha de las vasijas acampanadas.

\section{Aproximaciones a la imagen en movimiento desde la aplicación de técnicas analíticas}

Desde el siglo XVIII los investigadores reconocen las representaciones pictóricas y escultóricas de murales moche como fuentes de información directa de las costumbres, fiestas, creencias, actividades cotidianas y rituales de sus realizadores (Larco 1938, 1939; Kutscher 1955; Bonavia 1959, 1974; Klein 1967; Benson 1972; Mujica 2007; Uceda et al. 2010). La identificación de temas y la reconstrucción de secuencias en la iconografía moche facilita la identificación de actores centrales, elementos, escenas y su aparición en diferentes contextos, la concatenación entre representaciones diversas, como si las imágenes moche representaran un universo "discursivo reconstruible a partir de un corpus amplio de imágenes" (Golte 2009: 420-421).

Si bien los estudios iconográficos se han basado en la secuencia narrativa de Bourget (1994), sólo Makowski (2001), Mires (2006), Golte (2009), Hart (2010) y Campana (2015), mencionan la representación de movimiento en la iconografía 
como "un instrumento esencial para complementar las definiciones sobre relaciones de tiempo y espacio, en el mismo edificio y sitio, o con relación a otros casos en otras áreas o regiones" (Morales 2003: 427).

Hablar de movimiento es reconocer que existe una secuencia narrativa ${ }^{6}$ y rítmica ${ }^{7}$ en la iconografía. Su ritmo está dado por el orden de aparición de cada uno de los cuadros y escalones, por la separación intencional de las representaciones y la repetición sistemática de algunas de sus formas que evidencian cambios y permanencias en los personajes, otorgando dinamismo a las iconografías. Este tipo de iconografía se denomina secuencial y es definida como "una serie de secuencias iconográficas que describen en un mismo soporte y de manera dinámica un evento cotidiano o mítico, la transformación de un personaje o el movimiento del mismo" (López 2016: 46).

La iconografía secuencial permite la animación del discurso narrativo en diferentes ritmos que varían de acuerdo a los soportes (mural y cerámica) y formas de representación (separación en bandas o espacios entre representaciones). Para el caso de la cerámica de Huaca de la Luna es evidente que vasijas acampanadas repiten el ritmo de la secuencia de los murales, donde es posible diferenciar cambios morfométricos en representaciones zoomorfas y fitomorfas, siendo las representaciones de imagen en movimiento más comunes los peces, felinos y aves.

Dichas representaciones corresponden a un discurso naturalista incluyente de un código sonoro, dado por el movimiento de bolas de cerámica cocida que se encuentran al interior de la base de las vasijas acampanadas. Sólo al girar las vasijas se genera un mundo floral y animal en movimiento, nadan peces y se les dilatan las pupilas (Figura 4), jadean zorros, aves que mueven el pico y su cabeza de arriba hacia abajo. También existe un discurso ilusorio en la vasijas, aunque parecido al discurso naturalista; se distinguen por el tipo de representaciones serpentiformes, escalonadas y geométricas que generan nuevas imágenes a partir del giro.
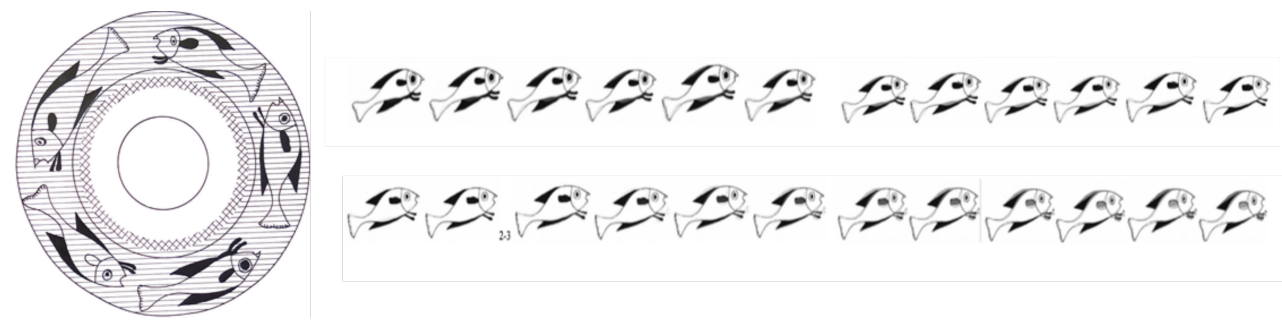

Figura 4. Vasija acampanada de Huaca de la Luna y descomposición de movimiento.

Un tercer tipo de discurso es el mítico, evidente en murales de adobe y piedra que hacen parte de fachadas o zonas laterales de estructuras arquitectónicas prehispánicas. Aparecen allí representaciones de seres míticos, "deidades" o personajes zoomorfos que evidencian variaciones morfométricas aún más complejas que las representadas

Las secuencias narrativas corresponden a "series ordenadas y continuadas de imágenes" que indican un orden de lectura, "cuentan una historia, describen un momento y expresan ideas sobre el cosmos, la naturaleza y la sociedad" (Golte 2009 en López 2016: 45).

7 "El ritmo de la secuencia está dado por la repetición sistemática, ordenada e intencional de los fotogramas, evidencia cambios y permanencias de los personajes, otorgándoles dinamismo” (López 2016: 45). 
en la cerámica. Los personajes se articulan a un lenguaje iconográfico que dialoga con el paisaje, las estructuras arquitectónicas y muy posiblemente con las escenas rituales o cotidianas que se celebraban en épocas prehispánicas; situaciones que motivaron la realización de un sistemático análisis, desde la secuencia gráfica, la cronofotografía y la morfometría geométrica, en Huaca de la Luna y Tula.

En el caso del Templo Viejo de Huaca de la Luna, Escalón 3 del frontis norte, se evidenció un personaje arácnido conformado por una parte anterior y una parte posterior que se transforma con el paso de los fotogramas. En la parte anterior se encuentra un personaje mostrado siempre de perfil cuyo rostro se transforma continuamente en animales y sólo por tres cuadros consecutivos presenta rasgos humanos (fotogramas 22, 23 y 24). Sin embargo, siempre se mantienen apéndices locomotores (entre 6 y 10), una mano humana y un objeto que sólo es cambiado por una cabeza en el fotograma número 20 . Al realizar la animación de la parte anterior del personaje se evidencian movimientos de flexión y extensión de los apéndices locomotores y las manos (Figura 5).

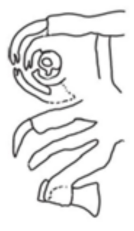

18

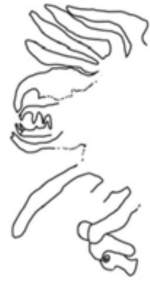

20

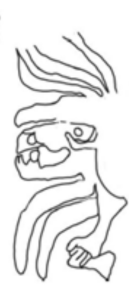

21

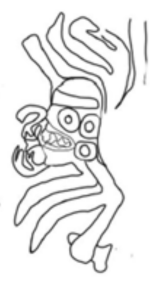

22

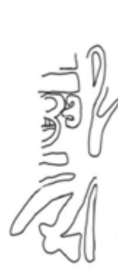

23

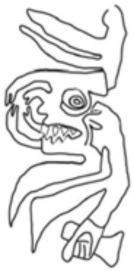

24

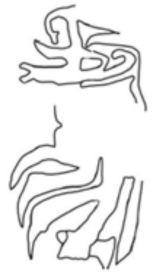

25

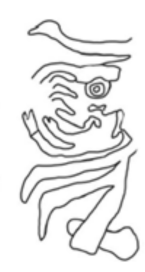

26

Figura 5. Movimientos de flexión y extensión en parte anterior del personaje del escalón 3, Huaca de la Luna (López 2016: 85).

En la parte posterior se percibe otro personaje mostrado de planta, como si estuviese siendo observado desde arriba, el cual muestra un vientre, entre 6 y 10 apéndices locomotores, dos manos - una de ellas humana-, y un objeto que aparece únicamente en el fotograma 31. El rostro de este personaje es zoomorfo y se transforma continuamente sugiriendo procesos de multiplicación celular. Al realizar la animación del escalón, se evidencian movimientos de abducción y aducción como si estuviera nadando (Figura 6).

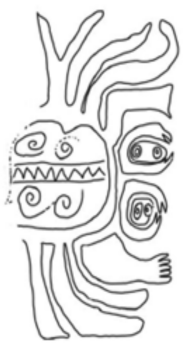

14

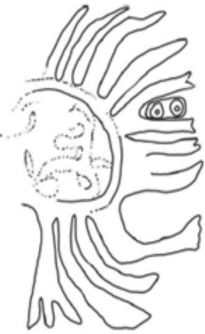

15

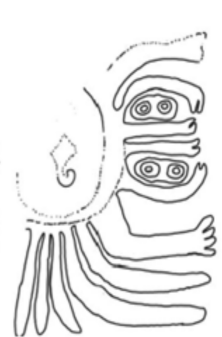

16

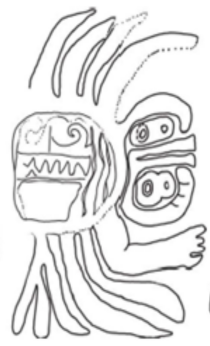

17

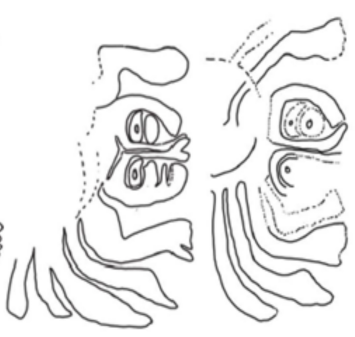

19

Figura 6. Movimientos de abducción y aducción en parte posterior del personaje del escalón 3, Huaca de la Luna (López 2016: 88). 
Los cambios morfométricos del Aiapaec son menores en la Plataforma 1, Templo Viejo de la misma Huaca. Sin embargo, al aplicar las técnicas y usar los programas de animación es evidente una transformación en el rostro del personaje, cuyas pupilas se dilatan, la nariz se infla, los dientes se agudizan y las olas (cabello) se extienden y contraen.

Para el caso de México, las condiciones de secuencialidad están distribuidas de distinta manera. Aunque se evidencian iconografías secuenciales en series de personajes zoomorfos que se intercalan, se hizo necesario separar las series de felinos y coyotes. Al separarlos y terminar el análisis morfométrico, se evidenció que todos los felinos conservan rasgos en sus patas, cabeza, cola y al parecer llevan en el cuello un collar con un objeto. Las variaciones en los ángulos de sus cabezas, patas y colas sugieren movimientos leves de pasos y levantamiento de cabeza por parte del felino (Cuadro 1).

\begin{tabular}{|l|c|c|c|c|c|c|c|c|c|}
\hline \multirow{2}{*}{ PARTES } & \multicolumn{3}{|c|}{ FELINOS } & \multicolumn{5}{|c|}{ FELINOS LADO ESTE } \\
\cline { 2 - 11 } & 1 & 2 & 3 & 1 & 2 & 3 & 4 & 5 & 6 \\
\hline $\begin{array}{l}\text { LADO NORTE extremidad delantera } \\
\text { izquierda }\end{array}$ & -1 & -24 & -15 & -35 & -20 & -5 & -10 & -4 & -8 \\
\hline $\begin{array}{l}\text { Punta extremidad delantera de- } \\
\text { recha }\end{array}$ & -40 & -35 & -30 & -20 & -50 & -60 & -60 & -70 & -50 \\
\hline Collar & 0 & 40 & 30 & 10 & N.A & 18 & 10 & 14 & 20 \\
\hline Vértice extremo de la oreja & -10 & 10 & 50 & -10 & 10 & 15 & 0 & 20 & 35 \\
\hline Cola & 10 & 90 & 0 & 90 & -10 & -2 & 1 & 20 & 90 \\
\hline $\begin{array}{l}\text { Punta extremidad trasera } \\
\text { izquierda }\end{array}$ & -20 & -15 & -10 & -45 & 15 & 10 & 5 & 10 & 20 \\
\hline $\begin{array}{l}\text { Punta extremidad trasera } \\
\text { derecho }\end{array}$ & -20 & -8 & -1 & -5 & -20 & -15 & -25 & -20 & -5 \\
\hline
\end{tabular}

Cuadro 1. Ángulos de cada una de las partes de coyotes y felinos de Tula.

En cuanto a los coyotes mencionados por Alvear (2004) y Jiménez (2008), no todos conservan la misma fisionomía y morfometría. Si bien permanecen algunos rasgos en las orejas y colas, parece no tratarse del mismo animal.

En el lado Norte del mural, se encuentra un panel más corto, aproximadamente de 7 metros; el cual parece formar parte de dos series separadas por una banda vertical. La serie elegida está completa y cuenta con cinco representaciones: un felino entre cuatro ¿coyotes? (Figura 7), todos están dirigiéndose hacia el mismo lado. La otra serie está incompleta y solo conserva un felino. Por tratarse de un análisis de iconografía secuencial, se seleccionaron los tres felinos del lado Norte del mural (Figura 8) y las seis representaciones de felinos del lado Este del mismo (Figura 9). Al realizar el análisis morfométrico se encontró que las imágenes no son iguales entre sí y las posiciones de la lengua, orejas, cabeza, cola, patas y collar varían de ángulo y posición espacial, sugiriendo movimientos leves para cada una de las partes. 

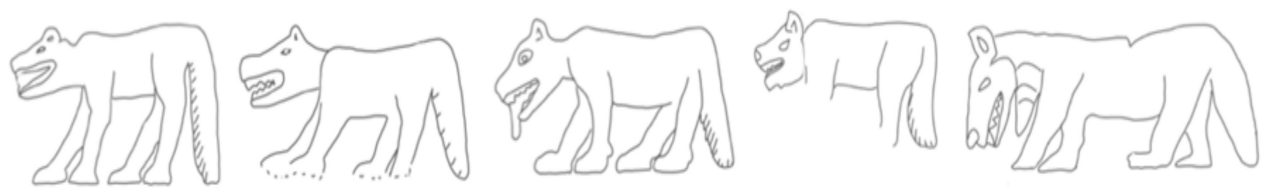

Figura 7. Coyotes del lado norte, Edificio B, Tula.

Si bien las representaciones de movimiento no se dan igual en Perú y México, es evidente su transformación intencional, que sugiere el concepto de imagen en movimiento. Martín (2010) recurre al planteamiento filosófico sobre la imagen-en-movimiento de Deleuze, Beckett y Bergson, ubicándola como un interés de la ciencia antigua que permitía "conocer suficientemente su objeto cuando ha notado sus momentos privilegiados" (Bergson 1963: 721); de ahí que se atribuya a Marey y Muybridge el interés por registrar el movimiento de los cuerpos. Sin embargo, la misma característica se aplica al mundo prehispánico.
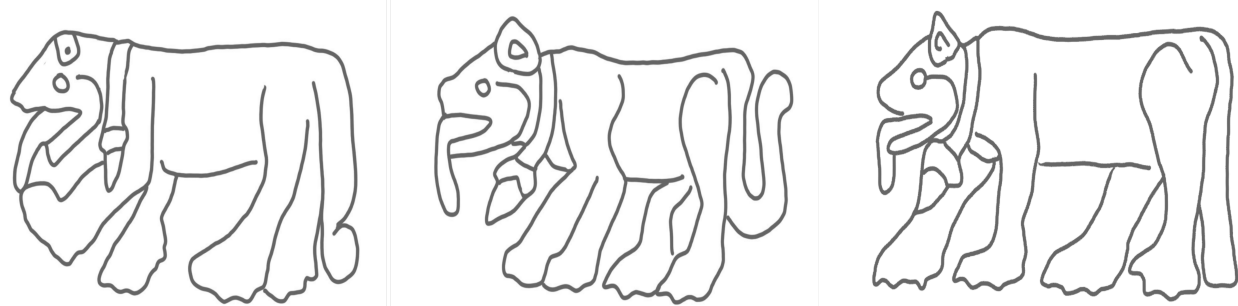

Figura 8. Iconografía secuencial en el Edificio B, lado norte. Tula

Moches y toltecas mostraron movimientos de traslación de diversos cuerpos en series y secuencias de un mismo personaje, sugiriendo la intención de movimiento en la imagen. Una ilusión que se da por "la idea abstracta de una sucesión, de un tiempo mecánico, homogéneo, universal y calcado del espacio" (Deleuze 1984: 1314). Idea no lejana a los antiguos pobladores, observadores en detalle de los objetos y seres que les acompañaron en ese presente, quienes comprendieron los principios de la serie y la secuencia para transmitir la ilusión en vasijas y murales, posiblemente en condiciones que hicieron viable la percepción del movimiento. Imágenes que probablemente fueron utilizadas como parte de los discursos, encuentros y ceremonias rituales, con el apoyo de luces y sombras que permitían la animación de las mismas, como ocurre en Europa (Azéma 2015).

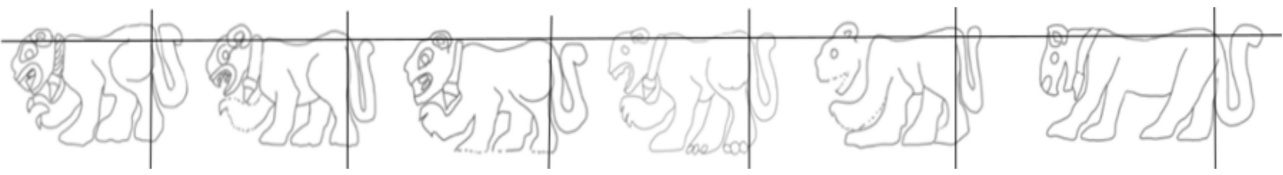

Figura 9. Felinos del 2 al 7 del lado este, Edificio B, Tula. Las líneas son los ejes referentes para la toma de ángulos.

Develar la forma de animación en los murales es uno de los retos pendientes que quedan para Perú y México. Por ahora solo podemos confirmar que, al girar las vasijas acampanadas de Huaca de la Luna, llamados también floreros sonajeros, la ilusión de movimiento de cada imagen se hace presente. Es notorio que las 68 vasijas halladas 
funcionan como zootropos o maquinas estroboscópicas que permiten animar la imagen mediante giros, dando la ilusión de movimiento en los animales que contienen.

\section{Consideraciones finales}

Los estudios iconográficos requieren métodos y técnicas que permitan comprender las imágenes en sus contextos, con ubicaciones en su propio espacio y paisaje. La aplicación de la cronofotografía y la morfometría se convierte en una herramienta para visualizar los cambios espaciales de los trazos y formas de las iconografías que conforman narrativas y se relacionan con los espacios arquitectónicos de los templos que parecen haber sido utilizados para actividades rituales.

En una lectura iconográfica del mural en Huaca de la Luna, López (2016) articuló el paisaje y permitió comprender, desde el cerro y el agua, los múltiples significados de los cambios morfométricos del ser arácnido y su influencia en el mundo dual de vida-muerte en el mundo Moche. Para el caso de Tula, se confirma la apreciación de "jaguares y coyotes caminando" (Alvear 2004: 38), que Bernal (1979) denomina como "procesión de jaguares".

La disposición espacial de las representaciones de Tula sugiere un desplazamiento de felinos y coyotes en sentidos NE-SO para el lado Este y SE-NO para el lado Norte del Edificio B. Por el estado de conservación solo se puede afirmar que el conjunto de animales del lado Este indican el ingreso al cerro artificial o pirámide, como si dentro se llevarán actos rituales con el elemento que llevan los animales en el collar (posiblemente un corazón).

Reconocer la intencionalidad del movimiento en estructuras murales y vasijas de cerámica sugiere la elaboración de iconos con la intención de transmitir un mensaje o idea. Sus narrativas intencionales no sólo cuentan escenas apartadas, sino que conforman series y secuencias de imágenes con códigos que sugieren, incitan y provocan al espectador mediante una sensación de dinamismo.

La intencionalidad de movimiento se relaciona con la agudización de los sentidos, el manejo de las tres dimensiones en las representaciones, los tamaños de los relieves y los actos públicos. Los casos estudiados hacen parte de murales que pertenecen a estructuras piramidales en recintos abiertos, posiblemente para un uso público y no privado, sugiriendo la intención de comunicar un mensaje, mediante discursos y espacios condicionados para ello.

\section{Referencias}

Alvear, Carlos. 2004. Historia de México. $2^{\mathrm{a}}$ edición. México: Limuda.

Azéma, Marc. 2007. «La décomposition de mouvement dans l'art paléolithique: réponse à Juan-Maria Apellaniz» International Newsletter on Rock Art (INORA) 48: 23-28.

-. 2010. L'art des cavernes en action. 2 Vols. París: Éditions Errance.

—. 2015. La préhistoire du cinéma: Origines paléolithiques de la narration graphique et du cinématographe. París: Éditions Errance.

Bateson, Gregory y Margaret Mead. 1937. Trance and Dance in Bali. Character Formation in Different Cultures: A Series. http://rhuthmos.eu/spip.php?page=imprimir_articulo\&id_article $=1556$. 
Benítez, Hugo A. y Thomas H. Püschel. 2014. «Modelando la varianza de la forma: morfometría geométrica, aplicaciones en biología evolutiva». International Journal of Morphology 32 (3): 998-1008. http://dx.doi.org/10.4067/S0717-95022014000300041.

Benson, Elizabeth P. 1972. The Mochica: A Culture of Peru. Londres: Thames and Hudson.

Bergson, Henri. 1963. «La evolución creadora», en Obras escogidas, pp. 433-755. Trad. José Antonio Míguez. Madrid: Aguilar.

Bernal, Ignacio. 1979. Great Sculpture of Ancient Mexico. Nueva York: Reynal \& Co. and William Morrow \& Co.

Bonavia, Duccio. 1959. «Una pintura mural de Pañamarca, valle de Nepeña». Arqueológicas 5: 21-53.

—. 1974. Ricchata Quellccani. Pinturas murales prehispánicas. Lima: Fondo del Libro del Banco Industrial del Perú.

Bourget, Steve. 1994. «El mar y la muerte en la iconografía moche», en Moche. Propuestas y perspectivas, Santiago Uceda y Elías Mujica, eds. pp. 425-447. Lima: Institut Français d'Etudes Andines, Universidad Nacional de Trujillo.

Campana, Cristóbal. 2015. Iconografía del pensamiento andino. Trujillo: Universidad Privada Antenor Orrego (UPAO).

Cobean, Robert H. y Alba Guadalupe Mastache Flores. 2007. «Tollan en Hidalgo. La Tollan histórica». Arqueología Mexicana 85: 30-35.

Deleuze, Gilles. 1984. La imagen-movimiento. Estudio sobre cine1. Barcelona: Ediciones Paidós.

Gallardo, Francisco. 2002. Antropología visual y documentalismo antropológico: historias y compromisos. Santiago de Chile: Museo Chileno de Arte Precolombino.

Golte, Jürgen. 2009. Moche. Cosmología y sociedad. Una interpretación iconográfica. Lima y Cusco: Instituto de Estudios Peruanos, Centro Bartolomé de Las Casas.

Hart, Laura. 2010. «Secuencias gráficas. Un recurso común entre el arte prehistórico y el contemporáneo». http://www.rupestreweb.info/arteprehistorico.html.

Hernández, Rafael. 2006. «Argumentos para una epistemología del dato visual». Cinta de Moebio. Revista Electrónica de Epistemología de Ciencias Sociales 26: 196-206.

Jiménez García, Esperanza E. 2008. Catálogo escultórico-iconográfico de Tula, Hidalgo: sus imágenes en piedra. Fundación para el Avance de los Estudios Americanos (FAMSI). http://www.famsi.org/reports/07027es/index.html.

Klein, Otto. 1967. La cerámica mochica. Caracteres estilísticos y conceptos. Scientia 130. Valparaíso: Universidad Técnica Federico Santa María.

Kutscher, Gerdt. 1955. Arte antiguo de la costa norte del Perú. Berlín: Gebruder Mann.

Larco Hoyle, Rafael. 1938. Los mochicas. Tomo I. Lima: Casa Editora La crónica y variedades S.A.

—. 1939. Los mochicas. Tomo II. Lima: Casa Editora La crónica y variedades.

López Estupiñán, Laura. 2016. Aportes a la interpretación de sitios arqueológicos con iconografías secuenciales. El caso de la cronofotografía en Huaca de la Luna, Moche, Perú. Tesis de Maestría en Arqueología Sudamericana. Escuela de Postgrado, Universidad Nacional de Trujillo.

López Estupiñán, Laura y Luis C. Rodríguez Pérez. 2016. «La cronofotografía y morfometría geométrica como técnicas analíticas en la interpretación de iconografías secuenciales del sitio arqueológico Huaca de la Luna, Moche, Perú». Maguaré 30 (1): 187-210.

Makowski, Cristobal. 2001. «Ritual y narración en la iconografía mochica». Arqueológicas 25: $175-203$. 
Martín, Jorge. 2010. «La imagen-movimiento. Deleuze y la relación Beckett-Bergson». Areté. Revista de Filosofía 22 (1): 51-68.

Meneses, Jorge, Sofía Linares, José Gómez y Margarita Peñaranda. 2009. «Excavaciones en el frontis norte y en la Plaza 1 de Huaca de la Luna», en Informe Técnico 2008. Proyecto Arqueológico Huaca de la Luna, Santiago Uceda y Ricardo Morales, eds., pp. 8-51. Trujillo: Universidad Nacional de Trujillo.

Mires, Alfredo. 2006. Qayaqpuma. Nosotros los cajamarquinos Vol. 4. Cajamarca: Red de Bibliotecas Rurales de Cajamarca.

Morales, Ricardo. 2003. «Iconografía litúrgica y contexto arquitectónico en Huaca de la Luna, Valle de Moche», en Moche hacía el final del milenio. Tomo I, Santiago Uceda y Elías Mujica, eds., pp. 425-476. Trujillo: Pontificia Universidad Católica de Perú, Universidad Nacional de Trujillo.

Mujica, Elías. 2007. El Brujo. Lima: Fundación Wiese, ING Fondos y AFP Integra.

Reyes, Aurelio de los. 1993. «Los futuristas y el cine». Anales del Instituto de Investigaciones Estéticas 64: 93-115.

Uceda, Santiago, Henry Gayoso y Ricardo Tello. 2010. «Parte I. Las investigaciones arqueológicas», en Moche. Pasado y presente, Santiago Uceda y Ricardo Morales, eds., pp. 23107. Trujillo: Patronato Huacas de Moche, Fondo Contravalor Perú-Francia, Universidad Nacional de Trujillo.

Zelditch, Miriam L., Donald L. Swiderski, H. David Sheets y William L. Fink. 2004. Geometric Morhometrics for Biologist: A Primer. Londres: Academic Press. 